\title{
Genetics and the practice of medicine: the future is here
}

Welcome to Genetics in Medicine, a new adventure for the American College of Medical Genetics. The publication of this issue of our journal inaugurates a process that actually began nearly ten years ago, before the official incorporation of the College, and represents the ideas and efforts of a large number of people who have made this a reality. Genetics in Medicine is now the official journal of the American College of Medical Genetics (ACMG), providing a means of communication among and distribution of new and developing information on genetics to College members, health professionals providing genetics services, practicing physicians in other areas of medicine, basic and applied scientists in academic and commercial endeavors, and biomedical libraries.

OK, you say, but do we need another journal in genetics? I think that we do. Medical genetics is a rapidly changing discipline. There has been an amazing increase in our base of knowledge that makes our specialty exciting and should make it alluring. Our abilities to understand complex syndromes and diseases, to make accurate diagnoses, and in some cases to treat them based on our genetic knowledge have changed the perception that medical genetics deals only with unusual or childhood conditions. Yet there are great stresses and a risk of discouragement in this era of genetic hype and expectations. The classic practices of medical genetics, even within the academic community, are difficult to support at best, and nearly impossible in many situations in which the economics are constrained and managed care is a reality.

To continue our success, we must look to the broad application of genetics across the disciplines of medicine. Our vision in Genetics in Medicine is that genetics plays a central role in the practice of medicine through the prediction and prevention of disease and the promotion of public health. All areas of medicine have genetic issues that require investigation and new methods for counseling, care, and prevention. This is an ideal time for a new journal that will address these issues and promote the application of genetic principles and methods broadly.

The mission of Genetics in Medicine will be to enhance the integration of genetic knowledge into medical practice and provide a forum for genetic education in medicine. To accomplish this, our editorial board of talented members of the College represents clinical genetics, biochemical genetics, cytogenetics, molecular genetics, common disease genetics, genetic counseling, genetic epidemiology, public health genetics, genetic education, and clinical informatics. Original articles and reviews presenting high-quality clinical and laboratory research on genetics will be the major focus of Genetics in Medicine. As the official journal of the College, we will publish papers that will improve the practice of medical genetics, but we will not be limited only to clinical papers. Basic and applied laboratory research that increases our understanding of the genetic components of disease will also be published; this will be particularly relevant as medical genetics extends to common diseases, genetic epidemiology, and public health. We want Genetics in Medicine to represent us in our present activities and help guide us into new and evolving areas that will benefit from our talents and perspectives. It also seems clear that this should be international in scope and not limited to issues relevant only to the United States or the College. Every reader should look forward to the journal because the papers are timely, relevant, and aid in the education and practice of genetics in all areas of medicine.

Two interesting and evolving sections of Genetics in Medicine will be Clinical Informatics and Continuing Medical Education (CME). Clinical Informatics will feature information on the availability and use of databases and web sites, and how these can be applied to the practice of medicine. As our web capabilities grow during the next year with the support of Lippincott Williams \& Wilkins, we plan to use the journal web site for online publication, as well as for expanding the availability of illustrations that can accompany published papers and brief reports. We also plan to use interactive web activities for CME. The ACMG is now accredited provisionally for two years by the Accreditation Council for Continuing Medical Genetics (see Newsletter section) to sponsor continuing medical education for physicians, and Genetics in Medicine is an ideal format to facilitate part of this activity. Our goal for the near future will be to identify individual articles for CME in each issue and to include methods for self-evaluation and review in the issue or on the journal web site so that College members can receive credit for participating in this activity.

We need your help to make this journal a success. We need you to submit your best manuscripts to Genetics in Medicine. We need you to encourage others to submit, to read regularly, to subscribe, and to recommend that their libraries subscribe. We need you to take a copy of the journal to your library and recommend that your library subscribe. We need you to send your meeting notices to the Editorial Office. We need you to recommend that your recruitment office place classified ads in Genetics in Medicine. We need you to view Genetics in Medicine as an international forum for presenting the application of genetics in medicine throughout the world.

It is my hope that our journal will reflect the excitement and hope that our colleagues share about genetics in medicine. The Editorial Board and Lippincott Williams \& Wilkins are dedicated to publishing a journal that will be on the forefront of genetics and that you will want to read, and we will work hard to make this a success. We will always be open to suggestions and comments and look forward to working with College members, physicians in other specialties, other health professionals, and biomedical investigators as we approach new and future challenges of genetics in medicine.

Richard A. King, MD, PhD Editor-in-Chief 